\title{
ARTÍCULOS
}

\section{El aburrimiento como emoción reactiva y revolucionaria: El caso de Chile*}

\author{
Boredom as a Reactive and Revolutionary Emotion: The Case of Chile
}

\author{
Josefa Ros Velasco \\ Universidad Complutense de Madrid \\ josros@ucm.es \\ ORCID iD: https://orcid.org/0000-0003-2763-1366 \\ Ignacio Moya Arriagada \\ Western University \\ ignaciomoyaa@gmail.com \\ ORCID iD: https://orcid.org/0000-0002-9730-3926
}

\begin{abstract}
Resumen: Este artículo presenta la hipótesis de que el aburrimiento pudo ser un factor decisivo en el estallido social que tuvo lugar en Chile en 2019. La misma se sustenta en otra hipótesis que postula que el aburrimiento puede convertirse en una emoción política capaz de desatar la revolución, cuando afecta a todo un pueblo. El objetivo principal del trabajo es explicar el marco teórico filosófico en el que se inscribe la segunda hipótesis y dar razones de por qué, de ser esta cierta, podría aplicarse al caso concreto de Chile. Primero se esboza una definición inédita del concepto de aburrimiento y se examina la literatura que describe el aburrimiento como una emoción reactiva y política. Después, se desarrolla el contexto sociopolítico chileno de los últimos cuarenta años en busca de factores aislables que puedan ser relacionados con la experiencia del aburrimiento. Finalmente, se presenta una línea de investigación original para testar ambas hipótesis en un proyecto más amplio que pretende poder predecir cuándo un sistema social está al borde del colapso por aburrimiento.
\end{abstract}

Palabras clave: Aburrimiento; Chile; dictadura; hastío; reacción; revolución.

Cómo citar este artículo / Citation: Ros Velasco, Josefa y Moya Arriagada, Ignacio (2021) "El aburrimiento como emoción reactiva y revolucionaria: El caso de Chile". Isegoría, 65: e11. https://doi.org/10.3989/ isegoria.2021.65.11

ABSTRACT: This paper introduces the hypothesis that boredom may be a decisive factor in the social outbreak that took place in Chile in 2019. It is based on another hypothesis that postulates that boredom can become a political emotion capable of unleashing a revolution when it affects an entire community. The main objective of the work is to explain the theoretical, philosophical framework in which the second hypothesis is inscribed and to give reasons why, if this is true, it could be applied to the specific case of Chile. In this sense, an unpublished definition of the concept of boredom is first outlined and the literature that describes boredom as a reactive and political emotion is examined. Then, the Chilean socio-political context of the last forty years is analyzed in search of isolatable factors that may be related to the experience of boredom. Lastly, an original line of research is proposed on which to work to test both hypotheses in a broader project that aims to be able to predict when a social system is on the verge of collapse because of boredom.

* Este trabajo se ha beneficiado de los proyectos: "Por una historia conceptual de la contemporaneidad. La contemporaneidad clásica y su dislocación: de Weber a Foucault" (PID2020-113413RB-C31), "Improvisation and emotional contagion. History and philosophy of emotional experiences (histex-impro)" (PID2019-108988GB-I00) e "Institución y Constitución de la Individualidad: Aspectos ontológicos, sociales y de derecho" (PID2020-117413GA-I00), financiados por el MICINN. 
Keywords: Boredom; Chile; Dictatorship; Weariness; Reaction; Revolution.

Recibido: 9 septiembre 2021. Aceptado: 14 octubre 2021.

Copyright: (C) 2021 CSIC. Este es un artículo de acceso abierto distribuido bajo los términos de la licencia de uso y distribución Creative Commons Reconocimiento 4.0 Internacional (CC BY 4.0).

\section{INTRODUCCIÓN}

El aburrimiento es una emoción negativa que conduce a quien/es la experimenta/n a reaccionar frente a la situación que lo genera, primero a través de su exploración y, después, instando al cambio, para acabar con el malestar que provoca. En su acepción más sencilla, el aburrimiento desaparece cuando el entorno se modifica. Sin embargo, existen situaciones que causan aburrimiento y que no se prestan fácilmente al cambio, convirtiéndolo en una vivencia que se cronifica y que, con el tiempo, se llega a transformar en una suerte de aburrimiento complejo que se traduce como hastío de vivir. Escapar de este tipo de aburrimiento requiere de una reacción mucho más explosiva que ha de romper con la situación recurrente e inamovible que lo desencadena. Cuando todo un pueblo se encuentra atravesado por una vivencia de estas características, el aburrimiento adopta tintes sociales y políticos hacia la revolución.

No es la primera vez en la historia que el conjunto de la sociedad se rebela frente al tedio generado por una situación sociopolítica. En la antigüedad, la necesidad de dedicar todo el tiempo a la polis y al autocultivo acabó provocando el rechazo de quienes encontraban aburrido el no disponer de tiempo para el ocio y el disfrute. Siglos más tarde, fue en gran parte el aburrimiento frente a los dictámenes caprichosos de un dios tiránico y su iglesia lo que estimuló el quiebre de los preceptos religiosos e impulsó la secularización que daría lugar a la modernidad. Tiempo después, el aburrimiento generalizado frente a la industrialización y la ética capitalista del trabajo desató la revuelta de un conjunto de pensadores que querían cambiar las condiciones de vida de los obreros y que consiguió establecer lo que conocemos hoy como el estado de bienestar. Incluso durante el siglo pasado, otro grupo de filósofos cansados de la cultura de masas dio rienda suelta a la crítica contra la sociedad del consumo, sin saber que la globalización haría fracasar la revolución frente a lo indistinto y que todavía tendríamos que esperar para ver llegar el colapso de este sistema (Ros Velasco, 2022 en prensa).
No sabemos dónde ni cuándo se producirá el próximo gran estallido frente al aburrimiento que emana de determinadas formas contemporáneas de organización social y política, cultural y económica, aunque podemos imaginar qué tipo de sistemas que todavía se practican en diversos rincones del mundo están cercanos a colapsar, a estallar, teniendo en cuenta los precedentes en otros lugares y tiempos. De lo que estamos ciertos es de que ese aburrimiento, cuando se vuelve profundo y se comparte por todo un pueblo, acaba siempre por promover la ruptura con el presente, dando paso a la exploración de lo siguiente de manera drástica. Porque, lejos de lo que se suele pensar, el aburrimiento no es un estado de pasividad conducente a la inercia.

Asumiendo esta aproximación teorética a la capacidad reactiva del aburrimiento, los autores de este artículo nos hemos preguntado si, de alguna manera, existen patrones en distintos momentos y lugares puntuales de la historia que permitan explorar hasta qué punto puede el aburrimiento ser causante de las revoluciones y las acciones que encaminan a algunos pueblos oprimidos a perseguir y lograr la emancipación. Lo que nos planteamos es descubrir si hay aspectos clave relacionados con la experiencia del aburrimiento que se repiten en distintos casos en los que los pueblos se ven sometidos a un entorno sociopolítico constrictivo ante el que acaban estallando. Pretendemos, en última instancia, llegar a estar en condiciones de establecer un modelo que facilite el análisis de los marcos sociopolíticos actuales en los que se repiten estos puntos comunes que generan aburrimiento profundo para poder anticipar los colapsos paradigmáticos que están por venir, beneficiando así la labor de los agentes sociales y políticos que deben garantizar un momento de transición que, aun siendo revolucionario, se cobre el menor número de vidas posible.

Para llevar a cabo esta tarea, hemos decidido comenzar acercándonos a un caso de estudio: el del Chile de la dictadura pinochetista y el estallido social que ocurrió en octubre del año 2019. En 
los casi veinte años que duró la dictadura chilena (1973-1990) se implementó un modelo de sociedad que atomizó y privatizó gran parte de la vida comunitaria que el país había logrado construir hasta ese momento. Impuesto sobre la base de muertes y torturas, los efectos sociales y económicos de dicho modelo se materializaron, por ejemplo, en un sistema de pensiones individualizado que revertía en hambre, en una educación que se financiaba con el aporte monetario de cada familia o en una sanidad de pago. Durante este tiempo, la comunidad y el sentido de pertenencia fueron destruidos por completo. En su reemplazo, se levantó el relato del esfuerzo y la superación individual como únicas formas de asegurar el acceso a los servicios básicos. Los chilenos vivían juntos, pero a la realidad se enfrentaban de uno en uno. La vida se redujo a una carrera por poner comida sobre la mesa y entregar educación a los hijos. El horizonte se empequeñeció; el futuro apenas se vislumbraba.

Entonces, los chilenos se aburrieron. Al principio, se aburrieron de un Estado en el que las injusticias y los abusos eran la rutina. Después, de una situación económica y social que no cambió durante los siguientes treinta años de gobiernos democráticos. Terminaron por aburrirse de una existencia monótona y de sus propias vidas. Este aburrimiento creó una sensación generalizada de falta de sentido y propósito en la vida de los ciudadanos. Para algunos, trabajar largas horas para subsistir y asegurarle un mínimo bienestar a sus seres queridos era motivación suficiente para continuar. Pero una vida así, dedicada a sobrevivir, es una vida que tarde o temprano invita al cuestionamiento. Al menos esta es la sensación que ha quedado a los herederos de aquel triste periodo de la historia de Chile.

El aburrimiento profundo pudo ser, en parte, catalizador del movimiento popular más importante ocurrido en Chile desde el fin de la dictadura en 1990: el estallido social que cambió el destino de este pueblo. Porque los chilenos se alzaron con la convicción de que no merecía la pena una vida en la que morir de aburrimiento era una posibilidad real. Se dieron cuenta de que los problemas de uno eran los problemas de todos. A su vez, esto posibilitó el surgimiento de un sentimiento colectivo, un renacimiento del sentido de pertenencia que la dictadura había erradicado. Los chilenos recordaron que la vida era más que sobrevivir, que no tenía por qué ser aburrida.

Aunque en esta pequeña presentación del caso pueden pronto rastrearse elementos comunes a todo régimen opresor (desigualdad, atomización, individualización, ruptura de la identidad, injusticia, racionalización, etc.) y podemos imaginar que de todo este conglomerado rezuma un aburrimiento existencial insoportable, lo cierto es que esto son solo hipótesis. Hasta la fecha, no se ha demostrado que 1) el aburrimiento tenga una presencia importante en las vidas de quienes padecen las calamidades de la dictadura (chilena o de cualquier otra naturaleza), ni tampoco se ha probado que 2) el aburrimiento sea el que dispone la capacidad de movilizar a la gente, de incentivar la conexión con los otros para crear una narrativa superior, nacional, que apele a las grandes ideas de justicia e igualdad. En otras palabras, no se ha llevado a cabo ningún trabajo de naturaleza empírica que tome un caso de estudio a partir del cual averiguar si, realmente, el aburrimiento es clave en estos contextos represivos y si es un motor fundamental para el cambio.

En este ensayo no vamos a tratar de testar ninguna de estas hipótesis. Como punto de partida para poder hacerlo con éxito en el futuro, lo que aquí se presenta es la base teórica en la que se sustenta la idea de que algunas formas de aburrimiento son reactivas y pueden dar lugar a una reacción colectiva, cuando se experimentan en determinadas circunstancias por un pueblo. Además, se describe en detalle el contexto chileno que queremos conocer en profundidad para enfocar un futuro trabajo de campo capaz de arrojar luz sobre las hipótesis 1) y 2). Así las cosas, en este texto se plantea la teoría y se delimitan los pasos a seguir para testar las hipótesis a partir de cuya confirmación, por medio de un estudio de campo, llegado el caso, esbozaremos la posibilidad de crear un modelo de análisis comparativo sobre la base de la experiencia chilena con aplicación a contextos similares pasados o, en el mejor de los casos, futuros.

En resumen, este trabajo es la primera pieza de un proyecto mayor que se divide en las siguientes fases:

1. Exposición del marco teórico y planteamiento de las hipótesis de trabajo.

2. Validación de las hipótesis en el marco chileno.

3. Si se produce la validación, se reproducirá el procedimiento en otros contextos similares (ej., España).

4. Extracción de resultados.

5. Conclusiones e implicaciones en la práctica.

Los resultados esperados, siguiendo la propuesta anterior, son los que se especifican a continuación:

1. Revisión literaria y ensayo teórico. 
2. Trabajo de campo en Chile.

3. Trabajo de campo en otros contextos similares (ej., España).

4. Listado de puntos comunes entre todos los casos de estudio.

5. Protocolo para el estudio y la anticipación de situaciones de colapso por aburrimiento.

Teniendo en cuenta lo anterior, en el siguiente apartado expondremos el marco teórico en torno a la idea de que el aburrimiento es una emoción reactiva que, en algunas de sus formas, es capaz de llevar a pueblos enteros a la revolución. Para ello, se recuperarán y analizarán algunas partes de la investigación postdoctoral realizada por la experta en estudios de aburrimiento Josefa Ros Velasco (2022 en prensa), que recoge la literatura esencial en torno a esta teoría y la presenta de manera sistematizada. Seguidamente, el filósofo chileno Ignacio Moya Arriagada, académico en las áreas de la filosofía existencial, pesimismo y teoría de las emociones, llevará a cabo una disertación sobre las condiciones del paradigma chileno que han dado lugar al planteamiento de las mencionadas hipótesis.

Resta hacer explícito que la razón por la cual se ha escogido Chile como primer caso de estudio es precisamente el conocimiento por parte de ambos autores de su contexto sociopolítico, que ha despertado la inquietud por la idea de que el aburrimiento jugó un papel esencial en el devenir del pueblo chileno hacia la libertad, a partir de comentarios recibidos por distintos colegas de la academia. De la misma manera, como anunciamos más arriba, un segundo caso de estudio podrá estar centrado en el paradigma de la dictadura franquista española. En caso de requerir de más estudios de campo para la obtención de resultados, habremos de contar con la ayuda de investigadores provenientes de otros contextos que nos puedan asistir en la tarea a la que damos comienzo.

\section{EL CARÁCTER REACTIVO DEL ABURRIMIENTO SITUACIONAL COLECTIVO CRONIFICADO}

El aburrimiento es un estado que todos los seres vivos con un nivel de desarrollo cognitivo suficiente experimentamos con mayor o menor frecuencia, en todo lugar y tiempo, dependiendo tanto de factores exógenos, que obedecen a las posibilidades del entorno, como endógenos, relacionados con el sujeto. Se caracteriza por ser molesto hasta el punto de que no podemos ignorarlo y nos vemos obligados a hacer cualquier cosa para desasirnos de él.

No existe una definición consensuada por parte de los expertos sobre qué es el aburrimiento. Quizá una de las más aceptadas por la comunidad es la propuesta en el modelo MAC de Westgate y Wilson (2018). Según esta (2018, p. 689), el aburrimiento es un estado molesto "resultado de (a) un componente atencional, a saber, un desajuste entre las demandas cognitivas y los recursos mentales disponibles y (b) un componente significativo, a saber, un desajuste entre la actividad y los objetivos valorados (o la total ausencia de objetivos valorados)". Dicho de otro modo, el aburrimiento es un estado desagradable que "aparece cuando los sujetos se sienten incapaces o reacios a comprometerse cognitivamente con una actividad" (2018, p. 693) o una situación, aunque quieran hacerlo. Esto se produce en dependencia tanto de condicionantes ambientales (que conllevan por hipoestimulación o hiperestimulación a la ruptura del flujo entre el sujeto y el entorno), atencionales (que remiten a las particularidades individuales) o funcionales (que ofrecen información sobre la relación coste-beneficio). En la literatura especializada sobre aburrimiento, esto se conoce como state-boredom; en la filosófica y la artística como aburrimiento pasajero o aburrimiento sencillo. Es aquel que desaparece cuando la situación cambia (Ros Velasco, 2022 en prensa).

Pero hay otras experiencias asociadas al aburrimiento que no se contemplan en esta definición. Por ejemplo, lo opuesto a esto sería el chronic boredom, que se utiliza para referir a aquellos individuos cuya propensión al aburrimiento es tan alta, sea cual sea el motivo - sus rasgos de personalidad o un trastorno de la conciencia, como apuntan los psicoanalistas, o alguna deficiencia desconocida a nivel neurológico, como dirían los cognitivistas-, que siempre se encuentran aburridos, independientemente de que la circunstancia cambie (Ros Velasco, 2022 en prensa). Esto, sin embargo, no es exactamente igual a lo que los intelectuales del pasado llamaron aburrimiento complejo o aburrimiento profundo en la literatura y la filosofía.

El aburrimiento complejo o profundo también tiene que ver con la personalidad y las características individuales del sujeto, así como con el entorno. Sin embargo, su raigambre existencialista lo vincula más con lo que se conoce como el hastío de vivir, el descontento frente a la realidad, el cansancio de la existencia tal y como es. La diferencia entre aburrimiento crónico y aburrimiento complejo es que el primero solo puede darse de manera individual, en dependencia de las características del propio sujeto, mientras que el aburrimiento profundo puede darse individual- 
mente, en dependencia de la propia persona y del contexto, o de manera colectiva, cuando todo un grupo de sujetos siente el cansancio frente a lo dado en una determinada circunstancia compartida que no cambia y que parece cronificarse. Ros Velasco (2022 en prensa) ha puesto precisamente la mirada en si el aburrimiento dependiente de la situación puede llegar a cronificarse en el tiempo debido a la falta de cambio en el entorno, independientemente del individuo o del conjunto que lo padece, resultando en la desesperación en la que se gesta el aburrimiento conocido como profundo o complejo.

Así las cosas, parece que, aunque no tenemos una definición única de aburrimiento, sí contamos con una tipología del aburrimiento que puede ayudar a entender este fenómeno tan complejo y, a la vez, tan común (Ros Velasco, 2022 en prensa). Siguiendo lo anterior, el aburrimiento puede tomar las siguientes formas (Figura 1):

1. Aburrimiento dependiente del entorno, sencillo o pasajero, a nivel individual (un sujeto se aburre en una situación determinada y su aburrimiento desaparece cuando esta cambia).

2. Aburrimiento dependiente del entorno, sencillo o pasajero, a nivel colectivo (un conjunto de sujetos se aburre en una situación determinada compartida y su aburrimiento desaparece cuando esta cambia).

3. Aburrimiento dependiente del individuo, sencillo o pasajero (propensión de cada sujeto al aburrimiento, cuya experiencia desaparece al cambiar el entorno).

4. Aburrimiento dependiente del individuo, crónico (un sujeto se aburre de manera patológica en toda circunstancia o en un alto número de situaciones por razones psíquicas o neurológicas, independientemente de la situación).

5. Aburrimiento dependiente del entorno, crónico, a nivel individual (un sujeto se aburre a causa de una situación que no cambia y ante la que no puede reaccionar, aunque quiera, debido a la propia situación).

6. Aburrimiento dependiente del entorno, crónico, a nivel colectivo (un conjunto de sujetos se aburre a causa de una situación compartida que no cambia y ante la que no pueden reaccionar, aunque quieran, debido a la propia situación).

7. Aburrimiento complejo: cansancio frente a la realidad que genera sensación de sin sentido, en que derivan las experiencias de aburrimiento crónico a largo plazo, tanto a nivel individual como colectivo, y que requieren de reacciones extremas para cambiar la situación.

\section{Aburrimiento}

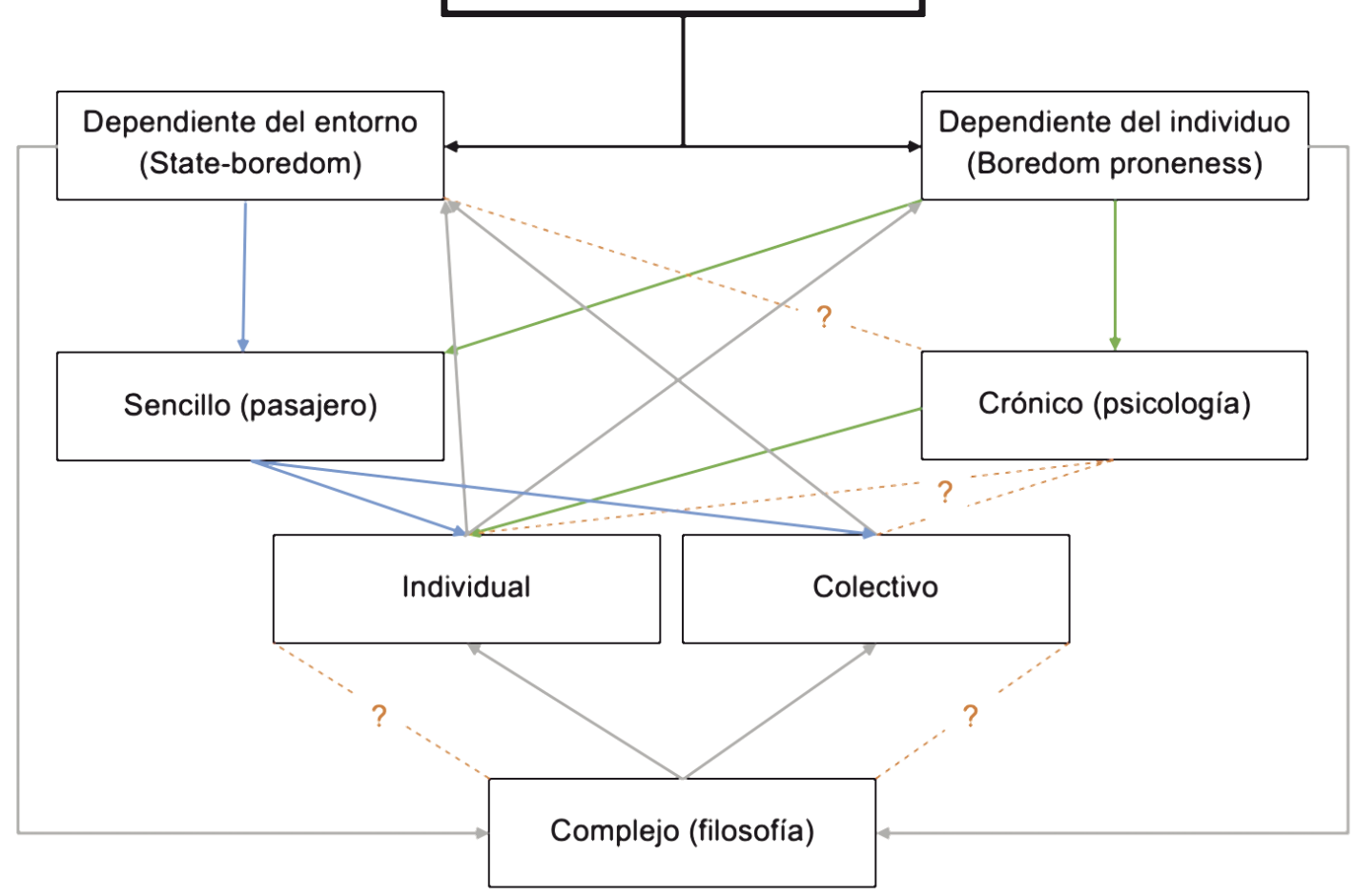

Figura 1. Mapa conceptual simplificado sobre tipos de aburrimiento y su relación (Ros Velasco, 2022 en prensa). 
Estos acercamientos al aburrimiento no son exhaustivos ni tienen en cuenta las variaciones en su experiencia en relación con cada periodo histórico y punto geográfico. Sabemos que ennui, Langeweile o noia, traducciones todas ellas de aburrimiento o boredom, son utilizadas indistintamente cuando, en realidad, cada término nace en el seno de un contexto sociocultural particular, en una época concreta. Así, ennui tiene mucho que ver con lo patológico y la metáfora del aburrimiento como enfermedad individual y colectiva que deviene tanto de la situación como del individuo, pero especialmente de la primera. Langeweile, sin embargo, está más encaminada hacia la experiencia temporal y encajaría más con el aburrimiento situacional entendido como aburrimiento sencillo. Estas expresiones en ocasiones se han empleado para referir al state-boredom y otras al profound boredom. Y, aunque no podemos detenernos en todas ellas, es bueno tener en cuenta que existen muchas más experiencias del aburrimiento y relacionadas con el aburrimiento (melancolía, anhedonia, neurastenia...) que no se contemplan en esta tipología (Ros Velasco, 2022 en prensa).

A pesar de las dificultades que entraña el ejercicio de definición del aburrimiento, todos sabemos que la experiencia del aburrimiento es molesta, incluso dolorosa. Cuando nos aburrimos parece que el tiempo se detiene y la vida se vacía de sensaciones. Mientras estamos aburridos tenemos la fastidiosa impresión de que el tiempo pasa más despacio. Por el contrario, cuando rememoramos el momento en que lo estuvimos nos enfrentamos al recuerdo de una experiencia hueca de impresiones que nos trae a la conciencia la cortedad de la vida y la culpabilidad del tiempo desaprovechado.

$\mathrm{Si}$ bien decíamos antes que el aburrimiento puede ser muy distinto dependiendo del individuo y del contexto, lo que no puede negarse es que ese aburrimiento une a todos los que lo padecen en una de las sensaciones más incómodas que pueden vivirse, una tan potente que no puede ser ignorada. El aburrimiento trae consigo la sensación de lo desagradable y de la escasez que se desea dejar atrás. Nos hace sentir una irritación provocada por una "conciencia de sí que se torna incómoda: como conciencia de un sí mismo en punto muerto, superfluo, que no se considera aludido y que no se ha pronunciado sobre nada" (Blumenberg, 2011, p. 528). Los expertos explican que este estado de insatisfacción psicológica, frustración o negatividad es en realidad el resultado del descenso de los niveles de excitación cortical que tiene lugar cuando nos enfrentamos a situaciones o realidades sin interés, monótonas o repetitivas, de acuerdo con la teoría psicodinámica, las hipótesis de la excitación y la teoría de flujo, y que se experimentan como carentes de sentido, siguiendo las teorías del significado (Ros Velasco, 2022 en prensa).

Esa sensación desagradable que no se puede desatender nos hace reaccionar inevitablemente (Neu, 1998) - a menos que padezcamos un trastorno de aburrimiento crónico por algún motivo de los aducidos más arriba-, pues está en nuestra naturaleza y la de todas las criaturas el huir del dolor. El aburrido pronto empieza a ser consciente de que algo no va bien y desea cambiarlo. Así, en un primer momento, nos damos cuenta de que en nosotros se está produciendo un desprecio por lo presente (Retana, 2011). Al ser conscientes de nuestro descontento, nos encaminamos hacia la acción introspectiva y la reevaluación cognitiva, nos sentimos curiosos frente a lo que tenemos delante y a lo que está ausente, e indagamos en su forma. En este punto, el aburrimiento representa una oportunidad para aprender de uno mismo y del contexto, convirtiéndose en un mecanismo de anticipación. Un segundo momento de reacción nos lleva precisamente hacia ese cambio, hacia la acción, desembocando en algún tipo de consecuencia. En este sentido, el aburrimiento no solo alerta mediante sus síntomas de que algo debe cambiarse, sino que, además, abre la puerta a la acción para promover dicho cambio (Blumenberg, 2011).

El aburrimiento nos impulsa siempre a emprender un movimiento para escapar de él, a expandir la vida atrayendo lo nuevo. Pertenece a las pasiones impulsoras más fuertes del ser humano, actuando, al principio, como una fuerza paralizante que, a continuación, desencadena una repulsión violenta ante lo que lo provoca. Lejos de representar un estado de pasividad, es reactivo. En realidad, podemos decir que en el aburrimiento hay un doble componente reactivo: por una parte, atendemos al momento reactivo de tomar conciencia de la situación para después dar paso a uno reactivo que implica algún tipo de acto para cambiarla. No es extraño que muchos hayan coincidido en decir que el aburrimiento es una señal; una que pone de manifiesto nuestra relación con el entorno y con nosotros mismos y que nos insta a desarrollar una estrategia para explorarlo o explorarnos y descubrir alternativas. Podríamos decir, al fin, que el aburrimiento es un síntoma.

Lo que hace precisamente que en ocasiones se confundan las formas del aburrimiento es que to- 
das comparten mucho de esto: en todos los casos se siente un malestar al que tenemos que prestar atención y todos conducen hacia una conciencia del momento o la situación presente. Sin embargo, no en todos los casos de aburrimiento está permitido el movimiento desde el análisis hacia el cambio. Esto es algo que no sucede con el aburrimiento crónico. En su lugar, se puede llegar al primer nivel de reacción, pero, sea cual sea el motivo, el propio individuo o el entorno, el segundo nivel nos está, en principio, vedado. A este segundo paso solo se accede a través de una fortísima repulsa, un estallido extremo que, como suele ser propio de los extremos, adopta formas inesperadas e incluso patológicas.

Lo curioso es que, siguiendo el planteamiento de Ros Velasco (2022 en prensa), en algunas circunstancias el state-boredom puede llegar a experimentarse como chronic boredom, a nivel individual y colectivo, cuando la situación es tan constrictiva que no cambia, hasta el punto en que su cronificación acaba por expresarse en forma de aburrimiento profundo, complejo, existencial, porque lo que comienza siendo aburrimiento frente a una determinada situación que puede cambiar, al no hacerlo, acaba invadiendo la vida en su totalidad. Con todo, en este caso, nuevamente, la cronificación es reversible a través de una reacción potente, especialmente cuando se experimenta de manera colectiva.

Cuando el conjunto de la sociedad se encuentra insatisfecho con el contexto es víctima también un aburrimiento que no solo le hace ser consciente de su desdicha como colectivo, sino que le empuja al cambio en un acto de rebeldía ante lo que provoca insatisfacción. Así, en muchas ocasiones a lo largo de la historia el aburrimiento ha actuado como fuerte contrapeso social, cuando menos se esperaba la reacción del pueblo. Como dice Retana (2011, p. 186):

Una cotidianidad monótona y enajenada, muy probablemente generará un aburrimiento colectivo. De hecho, y en esto coincide toda la filosofía crítica del siglo XX, la cotidianidad moderna lo genera. ¿Pero qué ocurre si una colectividad toma nota de ese aburrimiento generalizado y se levanta contra él? Quizá fue precisamente esto lo que ocurrió en la revolución de mayo de 1968, revuelta que algunos califican como una rebelión contra el conformismo y el aburrimiento.

En el fondo, a nivel colectivo, ante situaciones verdaderamente constrictivas en las que se pierde el sentido de la vida y la realidad, y que parecen extenderse hasta el infinito sin remedio, el carácter reactivo del aburrimiento hace que este se convierta en una emoción política (Ross, 2002), porque conlleva una carga emancipadora "aún no totalmente comprendida" (Gardiner, 2019, p. 301). El aburrimiento, desde este punto de vista, puede ser el punto de partida de grandes acontecimientos no solo a nivel individual sino también social. Llevaba entonces razón Cioran (1988, p. 151) al decir que la historia puede ser considerada el resultado del miedo al aburrimiento, "ese temor que nos hará siempre amar lo picante y lo novedoso del desastre, y preferir cualquier desgracia al estancamiento". A partir de este argumento, la historia se concibe como la tensión entre el aburrimiento y el estallido de lo nuevo, y el aburrimiento puede ser entendido como un marco analítico de causalidad de momentos históricos de transformación.

Se tiene la tentación de decir que la historia de la humanidad no es más que el intento de suprimir el aburrimiento. $\mathrm{O}$, si se quiere expresar de una manera más poética, podríamos afirmar también que el aburrimiento es "la sombra que guía nuestros impulsos hacia nuestro devenir y hacia nuestra historia" (Revers, 1967, p. 41). Solo por esto, algunos pensadores han llegado a defender que estar aburrido a veces es la única opción adecuada, porque el aburrimiento proporciona una especie de garantía de que uno está todavía en control de la propia existencia. El aburrimiento posibilita conocer el mundo y conocernos a nosotros mismos, ya sea como individuos o como sociedad, contiene el potencial reflexivo, contemplativo, que anima a imaginar alternativas y a explorarlas de facto.

El aburrimiento es el síntoma responsable de organizar la búsqueda de lo nuevo y de instigar momentos de experimentación y de expansión, a nivel individual y colectivo, de las formas más extremas cuando escapar parece imposible. Sin embargo, ello no significa que el resultado final de este proceso tenga que ser necesariamente positivo. Estas ideas no pueden llevarnos a afirmar sin más que el aburrimiento es algo bueno bajo el pretexto de que su experiencia nos hace ser creativos y revolucionarios. El aburrimiento puede, en efecto, incentivar nuestra creatividad, pero también nuestra destructividad o, lo que es lo mismo, la creación de monstruos que habitan en los extremos.

No hay que perder de vista en ningún momento que, más allá de las consecuencias, el aburri- 
miento solo es el que hace reaccionar; no se le puede responsabilizar de la reacción en sí. El aburrimiento no es la fuente ni de la creatividad ni de la destrucción, ni de la luz ni de la oscuridad. $\mathrm{Si}$ decimos que el aburrimiento es el responsable de que aumenten nuestros niveles de creatividad cuando observamos que algunos responden al mismo de manera creativa, en sentido positivo, entonces también tenemos que admitir que el aburrimiento es el culpable de que se produzcan comportamientos desviados y patológicos cuando otros tantos reaccionan a este de manera destructiva (Ros Velasco, 2021). A nuestro juicio, el aburrimiento solo nos va a hacer sentir mal, reaccionar ante el malestar y lo que venga después va a depender, nuevamente, de un amplio abanico de factores sociales y psicológicos.

Las personas creativas y sanas, en contextos opulentos, probablemente responderán al aburrimiento de forma creativa. En situaciones poco estimulantes, podrán hacerlo o no en dependencia de cómo de constrictivo sea el entorno. Esto es lo que, según la propuesta de Ros Velasco (2022 en prensa), puede suceder cuando el aburrimiento situacional se cronifica porque el entorno impide la reacción al ser demasiado limitado. Habrá quienes respondan bien, pero, por lo general, según se ha demostrado (Sommer et al., 2021), en estos casos se acaba reaccionando tarde o temprano a través de la impulsividad y la violencia. Por su parte, las personas destructivas en situaciones prolíferas de oportunidades podrán responder de forma positiva o negativa; pero lo que está claro es que cuando se une personalidad destructiva, enfermiza, con entorno limitado, el desenlace será nuevamente el estallido desmesurado. Y, en cualquiera de los casos, el aburrimiento no es ni bueno ni malo, simplemente es. Desde luego, es incómoda su experiencia, pero revestirlo de connotaciones morales es algo que obedece a los devenires sociohistóricos. Esto mismo puede aplicarse al plano colectivo.

Si hemos hablado de esta caracterización moral del aburrimiento es precisamente para introducir ahora la idea de que lo único que tiene de bueno aburrirse es que, sin su experiencia, la que nos hace reaccionar, nos quedaríamos atrapados en el presente doloroso hasta que este nos consumiese. En este sentido, de nuevo, el aburrimiento no es ni bueno ni malo: es funcional en términos adaptativos. La concepción del aburrimiento desde su funcionalidad está en la actualidad dando forma a una teoría que trata de enfatizar "el rol que las emociones juegan a la hora de transmitir información relevante sobre el entorno en el que nos encontramos inmersos" (Westgate y Wilson, 2018, p. 691). En resumen, persigue recalcar que el aburrimiento actúa como una señal incómoda y molesta que motiva el cambio cognitivo y de comportamiento en función del grado de utilidad de la acción, de lo motivadora que nos resulte y de los costes que lleve implícitos.

Sin embargo, más allá de esta aproximación, otros pensadores han mostrado que el carácter funcional del aburrimiento está precisamente en su potencial reactivo. Básicamente, el aburrimiento es funcional porque nos permite, como individuos y como sociedad, ser conscientes de una situación concreta, pensarla y sacar conclusiones sobre ella, moviéndonos a actuar en consecuencia para desterrar el malestar que se desprende de su experiencia. Con ello, facilita la construcción subjetiva del individuo y también del colectivo que se aburre. Pero la clave está en que, al provocar todo esto, el aburrimiento evita el estancamiento, facilitando así, por contrapartida, el movimiento, la evolución, el progreso (no necesariamente en sentido optimista).

Kant explicaba, en Antropología en sentido pragmático (2004), que nuestro objetivo primordial consiste en tratar de estar siempre lo más adaptados al entorno. Sin embargo, un exceso de adaptación tampoco es deseable, porque la comodidad en demasía es insoportable para el hombre. Además, el exceso de comodidad es peligroso, porque merma nuestra capacidad de reacción e impide que nos adaptemos a futuros cambios, apunta Blumenberg (2011). Las emociones negativas, entre las que contamos al aburrimiento, son precisamente las que nos ayudan a evitar el exceso de quietud. No es accidental que hayamos desarrollado la capacidad de aburrirnos (Elpidorou, 2020), sino que la hemos adquirido para experimentar el rechazo de las situaciones que se han vuelto demasiado cómodas y provocar la búsqueda de nuevas vivencias evitando la quietud y, con ello, la oxidación de nuestros mecanismos adaptativos (Ros Velasco, 2017).

En el intento de evitar el aburrimiento introducimos en nuestro contexto desajustes e irregularidades que ponen a prueba nuestra capacidad adaptativa y la fortalecen. El aburrimiento actúa como un nivelador de la vida esencial y necesario en términos adaptativos porque, por paradójico que parezca, mantiene un grado de desadaptación imprescindible para sustentar el estado de alerta frente a futuros peligros o cambios sobrevenidos, evitando el exceso de adaptación que nos condu- 
ciría a la muerte. Si hay algún sentido en el que podemos decir que el aburrimiento es positivo, es sin duda este.

\section{EL CASO DE CHILE: DICTADURA, ESTALLIDO SOCIAL Y ABURRIMIENTO}

Como ocurre con todos los eventos sociales, es en gran parte tarea de los historiadores y los sociólogos ofrecer lecturas e interpretaciones que nos permitan entender de mejor manera las causas y las motivaciones detrás de las revoluciones y los movimientos sociales en general. El caso de Chile no es una excepción. Teniendo esto en cuenta, aquí pretendemos ofrecer una lectura inicial acerca de la relación que hubo entre el estallido de 2019 y el aburrimiento para averiguar si el aburrimiento complejo, derivado de un aburrimiento situacional cronificado en el tiempo, fue un elemento fundamental a la hora de explicar lo que ocurrió en Chile y estudiar cuáles pueden ser los factores aislables que permitan extraer patrones comunes entre la sociedad chilena y otros pueblos del mundo - por ejemplo, 1) el que ese aburrimiento se produzca en grupos que viven bajo las condiciones de una dictadura, 2) el que se organice en un sistema económico de corte neoliberal, 3) el que fomente la ruptura de las relaciones sociales y el aislamiento o 4) el que la inseguridad y la incertidumbre sean protagonistas - .

El 11 de septiembre de 1973, el golpe militar liderado por el general Augusto Pinochet derrocó al gobierno del presidente constitucional Salvador Allende. Durante los siguientes diecisiete años, Chile vivió bajo una de las dictaduras más sangrientas de Sudamérica y del mundo entero. Los informes oficiales, en particular el Informe Rettig (Comisión Nacional de Verdad y Conciliación, 1991) y el Informe Valech (Comisión Nacional sobre Prisión Política y Tortura, 2004), dejan en evidencia la violencia de la dictadura y explican por qué las profundas heridas que esta dejó en la sociedad chilena aún subsisten. De acuerdo con los datos que aparecen en el Informe Rettig (1991) y en el Informe Valech (2004), durante el período de la dictadura hubo más de 30.000 víctimas, entre las que se incluyen 1.092 detenidos desaparecidos, más de 27.000 presos políticos y torturados y 102 menores de edad detenidos con sus padres o nacidos en prisión.

Todas las dictaduras se caracterizan por la represión, la muerte, la persecución y la falta de libertad, pero el caso de Chile es especial porque durante la dictadura de Pinochet se instaló un modelo económico que transformó de manera profunda y radical la fábrica social del país. Este tuvo como base la doctrina económica de Milton Friedman. Friedman, en ese entonces, era profesor de Economía en la Universidad de Chicago y un grupo de egresados de la Facultad de Economía de la Universidad Católica de Chile viajó a Chicago para estudiar sus propuestas económicas con el objetivo de implementarlas durante la dictadura chilena. Este grupo fue conocido como los Chicago Boys y, entre ellos, estaban los futuros ministros de Hacienda de Pinochet Sergio de Castro, Hernán Büchi y el que fue ministro de Trabajo José Piñera, quién se encargó de privatizar el sistema de pensiones para instalar el sistema de cotización individual conocido como AFP (Administradoras de Fondos de Pensiones). Las recetas económicas de Friedman, basadas en una mayor desregulación de la economía, fueron un aspecto central del programa económico de la dictadura chilena. El mismo Friedman dijo en una entrevista en el año 2000 que sus políticas estaban listas para implantarse tras derrocar a Allende (2012).

Friedman estuvo en Chile en el año 1975 y, durante su visita, se reunió con Pinochet. Una vez de regreso a Estados Unidos, le envió al dictador una carta de agradecimiento donde expresó, entre otras cosas, algunas de sus ideas para la reactivación de la economía. Entre estas destacaban

la eliminación de la mayor cantidad posible de obstáculos que, hoy por hoy, entorpecen el desarrollo del libre mercado. Por ejemplo, suspender, en el caso de las personas que van a emplearse, la ley actual que impide el despido de los trabajadores. En la actualidad, esta ley causa desempleo. También, eliminar los obstáculos a la creación de nuevas instituciones financieras. Asimismo, eliminar la mayor cantidad posible de controles sobre los precios y salarios. El control de precios y salarios no sirve como medida para eliminar la inflación; por el contrario, es una de las peores partes de la enfermedad. (Eliminar obstáculos, pero no sustituir subsidios. La empresa privada tendrá la facultad de gozar de las recompensas del éxito sólo si también arriesga soportar los costos del fracaso. Todo hombre de negocios cree en la libre empresa para todos, pero busca también favores especiales para sí mismo. Ningún obstáculo, ningún subsidio; ésa debiera ser la regla) (Friedman, 1975).

Producto de esas políticas que fueron implementadas y del consenso político que dominó el país durante cuarenta años, se consideró a Chile como un ejemplo de lo que puede lograr la buena gobernanza. Esto es particularmente cierto en el 
contexto de América Latina, donde las sucesivas crisis en Argentina, Brasil, Perú, Venezuela, Nicaragua y Honduras han ayudado a reafirmar aquella imagen de larga data de que América Latina es un lugar donde la corrupción y la inestabilidad son parte de la vida cotidiana. Pero Chile parecía una excepción en la región. Finalizada la dictadura, se consensuó una transición pactada que ha asegurado treinta años de gobiernos democráticos y cifras de crecimiento económico que, hasta antes de la actual pandemia, promediaron el $6 \%$ (Banco Mundial, s. f.). Junto a eso, se logró una dramática reducción de la pobreza - esta pasó del 40 $\%$ al $10 \%$ de la población - y hubo una completa ausencia de violencia política (Banco Mundial, s. f.). Sin embargo, después de todo, la pobreza y la represión han vuelto a aparecer. ¿Qué salió mal? Aunque las razones son múltiples y nosotros intentamos ofrecer una respuesta, lo cierto es que el modelo impuesto por la dictadura demostró no ser sostenible en el tiempo.

En Chile existió una sensación de indefensión que permeaba las vidas de los chilenos porque se sentían solos $-\mathrm{y}$ realmente estamos solos - . La crisis que se materializó en la más grande revuelta popular desde el retorno de la democracia fue únicamente posible gracias a la acumulación de una situación existencial incontenible. Fue existencial porque afectó el sentido de pertenencia. Fue estructural porque demostró tener el poder de afectar a las bases del actual sistema político y económico (Moya Arriagada, 2012). En el Chile que legaron Pinochet y los Chicago Boys, la plaza pública dejó de existir. Se privatizó tanto que se llegó a un punto en que el concepto mismo de país quedó muy debilitado. Lo hicieron atomizando la ciudadanía. Rompieron los lazos y las conexiones sociales, endosando las responsabilidades del bienestar social en cada individuo.

El país se desentendió, se lavó las manos. Los vecinos se despreocuparon. Cada uno velaba por su propia salud. Cada uno se ocupaba de su propia jubilación. Cada uno veía si podía o no dar una educación digna a sus hijos (Moya Arriagada, 2012). Por eso, mientras en otros países del mundo los gobiernos de derecha recortan los aportes públicos en salud, en Chile la salud ya tiene aportes públicos muy bajos porque su financiación se ha reducido a un tema individual, personal y privado; mientras en otros lugares se recorta el gasto público en educación, en Chile la educación es también un tema individual, personal y privado; y mientras algunos gobiernos hacen recortes a las pensiones de los ciudadanos, en Chile cada uno se preocupa de sus pensiones. En Chile no había nada que recortar. No era la función del Estado entregar esos servicios. Es, decía la historia oficial, responsabilidad de los individuos entregárselos a sí mismos (Moya Arriagada, 2012).

Lo anterior redunda en que, aunque la gran mayoría de los chilenos no podían proveer salud o educación de calidad a sus hijos, ni una jubilación digna para ellos mismos, de todas maneras, ocurría la curiosa situación de que las personas sentían que la culpa era de ellos exclusivamente. Los chilenos pensaban que no habían trabajado lo suficiente, que si solo hubieran estudiado más podrían haber obtenido un mejor futuro. El problema es que, en la mayoría de los casos, por mucho que los chilenos trabajaban, nunca tenían suficiente para tener acceso a educación, salud y jubilaciones dignas. El sistema impuesto a sangre y fuego por la dictadura de Pinochet tenía a muchos (y aún parece tener a muchos) convencidos de que las responsabilidades $-\mathrm{y}$, por lo tanto, las culpas - son siempre personales. Cada uno vivía casi como un ermitaño, en completo aislamiento (Moya Arriagada, 2012).

Entre los chilenos existía la sensación de que no había un país, que poco los unía. No había una comunidad. Lo que existía eran individuos que se relacionaban, no porque quisieran o porque relacionarse constituyera un aspecto fundamental de lo que significa vivir en un país. No, nada de eso. Como Hobbes y Locke ya advirtieron en sus respectivas teorías del contrato social (en el $L e$ viatán y en el Segundo tratado de gobierno), los chilenos vivían en sociedad solo porque a veces les convenía, porque peor sería vivir sin leyes. No existía un país detrás de las personas. Cada uno debía velar por sí mismo. Si alguien se quedaba sin trabajo no había cómo educar a los hijos. Aquel con la buena fortuna de tener una familia con recursos, tenía mayor seguridad y vivía con menos incertidumbre. Su familia era su comunidad, su país (Moya Arriagada, 2012).

Pero un día el hartazgo generalizado de los chilenos les movió a cambiar el modelo de sociedad radicalmente. Aunque las protestas sociales, particularmente las estudiantiles, han sido parte de la vida política en Chile, el día 19 de octubre de 2019 ocurrió un estallido social de proporciones nunca antes vistas. Apropiándose de su destino, Chile despertó para superar el legado de la dictadura dándose una nueva forma de organización social.

En términos concretos, el estallido ocurrió por un alza de la tarifa en el transporte público. 
Los santiaguinos ya gastaban hasta el $7 \%$ de sus ingresos mensuales en costear sus desplazamientos, lo que convierte a este sistema en el noveno más caro del mundo, según un estudio publicado por la Universidad Diego Portales (Ferrer, 2019). Una lectura adicional que serviría para explicar el estallido dice que la distribución desigual de la riqueza y las enormes desigualdades en el acceso a los servicios de salud, pensiones y educación finalmente alcanzaron un punto de erupción. $\mathrm{La}$ gente se hartó. Se hartó de un crecimiento económico que solo llega al $1 \%$ superior (Undurraga, 2019), se hartó de las pensiones que caen por debajo del umbral de pobreza (las pensiones medias son de $\$ 450$ al mes).

Otra explicación alternativa dice que el estallido social en Chile fue una protesta contra el dominio de la tecnocracia, una revuelta contra la regla de la imparcialidad, de la fría experiencia y la toma de decisiones objetivas. Para ser claros: no se dice que el problema es la imparcialidad o la objetividad en sí. Más bien, el problema es cómo se utilizaron estos conceptos para perpetuar un sistema de explotación que solo benefició y beneficia a los que están en el poder. Desde que los Chicago Boys se aliaron con la dictadura de Pinochet a principios de la década de 1980 para imponer medidas económicas que esencialmente redujeron el papel del Estado al mínimo, Chile ha funcionado en una especie de piloto automático, avanzando e implementando políticas públicas basadas casi exclusivamente en el análisis objetivo de varios indicadores económicos (Moya Arriagada, 2919).

Tomemos el alza de la tarifa del metro que al parecer inició el estallido. Este alzamiento fue decretado por un comité independiente de expertos que se reúne periódicamente para analizar y revisar el estado de la economía. La inflación, los precios de las materias primas y otros factores se analizan objetivamente para determinar si es necesaria una subida y en qué medida. La decisión de este comité no se puede apelar. Ninguna autoridad, ni el presidente, ni el Congreso, puede anularla. De esta manera, la experiencia y la tecnocracia dominan la política. Por eso, durante el primer y segundo día de las protestas, el gobierno siguió diciendo que no tenían poder para cancelar el aumento de tarifas. Esto solo enfureció más a la gente, fue echar leña a la hoguera. Finalmente, se vieron obligados a enviar al Congreso una propuesta que permitiría al gobierno anular las decisiones del comité. Esta fue la primera y bastante tardía concesión que hizo el gobierno. Si bien se procedió a hacer más concesiones (se aumentó la pensión mínima en un 20\% [Gobierno de Chile, 2019], lo que se traduce en aproximadamente \$27US mensuales, dado que, al momento de decretar este reajuste, dicha pensión era de \$135US [Superintendencia de Pensiones, 2019]), los chilenos entendieron acertadamente que esto no resuelve los profundos problemas estructurales, por lo que la gente siguió en las calles.

Después de todo, si un comité de expertos imparcial llega a una conclusión determinada, los políticos y figuras públicas pueden acusar inocencia y, de esa manera, eludir cualquier responsabilidad. Las decisiones se presentan como objetivamente válidas, sin motivaciones políticas $\mathrm{y}$, se supone, ninguna persona racional puede oponerse a estas conclusiones. Las decisiones en Chile se han tomado, y se siguen tomando, de esta manera en muchas áreas. Las tarifas de servicios públicos y los peajes de las carreteras son otros ejemplos. Los representantes públicos no juegan ningún papel que permita a los tomadores de decisiones decretar alzas sin tener en cuenta las ramificaciones sociales. Esta forma de hacer política, de conducir los asuntos de la nación, ha durado cerca de cuarenta años, hasta que Chile ha decidido ponerle fin. Hoy los chilenos se encuentran abocados a esa tarea.

El mayor logro del estallido fue la creación de una asamblea constituyente, la primera paritaria en el mundo. Esta asamblea tiene la tarea de redactar una nueva constitución para el país que reemplace la que rige desde 1980. La nueva constitución que saldrá de la asamblea en marzo del 2022 busca consagrar un rol esencial para el Estado y limitar la influencia de los privados en el suministro de los bienes sociales que la ciudadanía hoy demanda. En otras palabras, esta nueva constitución pretende construir un país nuevo, opuesto al que instauró la dictadura.

A nuestro juicio, todos estos hechos fueron, sin duda, determinantes, pero, por sí solos, insuficientes para explicar lo ocurrido el 19 de octubre. Sostenemos que el aumento de la tarifa no fue más que un catalizador para problemas mucho más profundos. Esta alza no hubiera generado el estallido social si no hubiesen estado presentes las condiciones existenciales relacionadas con el aburrimiento complejo. Pudo haber sido de cualquier otra manera, pero creemos que los chilenos hicieron de su aburrimiento compartido por una situación cronificada un arma valiosa para despertar y recuperar su autonomía y su libertad (Moya Arriagada, 2012). Recordaron que pertenecían a 
una comunidad y decidieron actuar para cuidarla. Al final, la vida en solitario, en aislamiento del resto, se presentó como intolerable, y en esto el aburrimiento complejo cumplió una función esencial.

Hay algunas evidencias que nos ponen sobre la pista de que el aburrimiento estuvo realmente presente en la erupción del estallido de hace dos años. Más allá de lo que se sustenta en la teoría introducida en el segundo apartado de este ensayo, el propio Pinochet ya anunció hace más de dos décadas, en una entrevista al diario El País (5 marzo 2000), que los chilenos se aburren fácilmente de sus gobernantes, aunque estos sean muy buenos: "El pueblo chileno se aburre, como se aburrió de mí. Por muy macanudo que sea el gobernante, el pueblo se aburre". Este aburrimiento fue la razón, según él, que explica su derrota en el plebiscito del 5 de octubre de 1989. El mismo dictador reconocía, entonces, que el aburrimiento jugó un rol en los cambios sociales.

Pero dejando a un lado las palabras de Pinochet, en los días posteriores al estallido también la prensa pudo recoger diversas opiniones de la población chilena que apuntan a respaldar esta sensación generalizada de aburrimiento. Un ejemplo es la expresada por la futbolista Lina Echeverry en una entrevista para $B B C$ News (26 de octubre de 2019), cuando dijo que "el chileno se mamó, se aburrió de vivir como subyugado". Otro lo encontramos en las palabras del investigador y escritor Fernando Arriagada Cortés para La ventana ciudadana (9 de mayo de 2021): "Chile se aburrió de la interminable transición y lentamente, por treinta años, luchó contra los enclaves autoritarios dejados por la dictadura".

Quizá uno de los ejemplos que mejor recoge la conexión entre aburrimiento y estallido sea el del actual alcalde de la comuna de Recoleta (en Santiago de Chile) y ex precandidato presidencial del Partido Comunista de Chile, Daniel Jadue, cuando explicó, en la columna del 28 de octubre de 2019, que

el pueblo [...] simplemente se cansó. El pueblo de Chile se aburrió de las alzas permanentes del costo de la vida mientras las utilidades de las grandes empresas, de las Isapres, de las AFP y de la banca siguen subiendo al tiempo que un ministro en ejercicio llamaba a comprar flores porque es lo único que baja de precio. Se aburrió de que los mismos que llaman antipatriotas a quienes no estamos de acuerdo con sus ideas y privilegios, lleven sus fortunas a paraísos fiscales [...]. Se aburrió que nos digan que mejo- rar las condiciones de vida de los sectores más vulnerables es imposible, porque según ellos no hay recursos, mientras vemos cómo se coluden todos los grandes empresarios de este país para aumentar sus utilidades a costa de encarecer el costo de la vida de los que menos tienen [...]. Simplemente no lo acepto [...]. Hoy los jóvenes despertaron y remecieron Chile, y ellos son los protagonistas principales.

El aburrimiento que pudo experimentarse en el caso chileno es del tipo 6, degenerando al tipo 7, esto es, aburrimiento dependiente de la situación experimentado a nivel colectivo que se cronifica, independientemente de las facultades de los individuos, porque el entorno no cambia ni posibilita la reacción de los sujetos que lo padecen, hasta convertirse, con el tiempo, en aburrimiento complejo que despoja la existencia de sentido, acabando, en un estallido extremo, por mover al pueblo hacia la revolución, gracias al componente reactivo que radica en toda forma de aburrimiento. En el caso que aquí nos compete, la reacción ante el aburrimiento complejo fue extrema, propia de las salidas a esta forma de aburrimiento, pero positiva, porque fue el empuje decisivo para poner fin a la transición que ya llevaba treinta años de duración.

\section{CONCLUSIONES Y DECLARACIÓN DE INTENCIONES}

El aburrimiento que surge de un sistema que puede mejorar, pero no lo hace, impulsa a la sociedad al cambio. Quizá fue precisamente esto lo que sucedió en la historia reciente de Chile. Por el momento, no lo sabemos a ciencia cierta, pero tenemos buenas razones para sustentar las dos hipótesis que se han planteado en este trabajo inicial y continuar con nuestro esfuerzo para testarlas.

Una de ellas postulaba que el aburrimiento, en sus distintas formas, es casi siempre una emoción reactiva que, a través de dos movimientos, lleva a quien o quienes la padecen a la conciencia sobre una determinada situación y, después, a la acción para conseguir el cambio de esta. Y ello porque el aburrimiento es tan molesto que su experiencia no se puede ignorar. Y tiene que ser así, precisamente, para hacernos reaccionar, consiguiendo con ello impedir la sobreadaptación y la excesiva quietud que nos puede condenar a quedarnos atrapados para siempre en una circunstancia cualquiera. La literatura hasta el momento apoya esta hipótesis, como se ha demostrado, aunque nunca se ha tratado de validar a partir del estudio de un caso concreto. 
La otra hipótesis planteaba que la dictadura chilena y las políticas que la sobrevinieron, como caso específico, habrían sido el caldo de cultivo perfecto para el tipo de aburrimiento que hemos descrito como situacional colectivo tornado crónico y, en última instancia, complejo, y su reacción asociada a través del estallido revolucionario. Las características aislables de este contexto serían, en principio, 1) opresión dictatorial, 2) sistema económico de corte neoliberal, 3) experiencia de soledad/aislamiento y 4) sensación de incertidumbre e inseguridad. Por el momento, los testimonios recogidos a través de la prensa y la literatura parecen apuntar en esta dirección.

Lo que ahora queda por delante es comprobar si estamos o no en lo cierto. El siguiente paso después de haber sentado la base teórica de nuestro trabajo debe necesariamente consistir en el diseño de un estudio de investigación cualitativa que permita comprobar si, en efecto, el aburrimiento, en alguna de sus facetas, estuvo presente en el Chile de la dictadura y de después de la dictadura y, de ser así, averiguar si ese aburrimiento se sintió como el impulso hacia la búsqueda de alternativas. Para ello, habremos de embarcarnos en una serie de entrevistas en profundidad con una muestra de los chilenos que vivieron la dictadura y el estallido de 2019 de cerca. Así, estaremos en condiciones de esclarecer, en primer lugar, la relación del aburrimiento con los factores aislables que se han expuesto en el apartado anterior (opresión dictatorial, sistema económico de corte neoliberal, experiencia de soledad/ aislamiento, sensación de incertidumbre e inseguridad).

Si este primer paso confirma nuestras hipótesis, todavía será necesario explorar otros contextos parecidos, coincidentes con los descritos por quienes apelan a que el aburrimiento, en determinadas formas, puede llevar a la revolución, convirtiéndose en una emoción política, para observar si los resultados se repiten de un escenario a otro y extraer patrones comunes a partir de los factores aislables. Aunque esto es poner la mirada en el futuro a largo plazo, otro de los posibles países sobre los que trabajar podría ser España, a partir de la experiencia del franquismo. Más escenarios requerirán de la entrada de nuevos investigadores que harán grande este proyecto que aquí iniciamos y cuyo recorrido todavía está por ver.

En definitiva, nuestra intención, si demostramos llevar razón, no es otra que la de llegar a comprender mejor el mecanismo bajo el que opera el aburrimiento situacional colectivo que se cronifica y se experimenta como complejo en situaciones similares, esto es, saber cuáles son sus causas exactas y sus consecuencias, para estar en disposición de elaborar un modelo de mínimos, de puntos en común, de factores aislables que se repiten, que se pueda extrapolar entre Estados y que facilite la anticipación de colapsos de sistemas sociales, pudiendo suavizarse así la transición a lo nuevo, o lo que hemos llamado "estallido social", esto es, los efectos de las respuestas extremas.

\section{BIBLIOGRAFÍA}

Arriagada Cortés, F. (9 de mayo de 2021). Poder ejecutivo a la deriva. La ventana ciudadana. https:// laventanaciudadana.cl/poder-ejecutivo-a-la-deriva/.

Banco Mundial (s. f.). Chile. https://data.worldbank. org/indicator/.

Blumenberg, H. (2011). Descripción del ser humano. Fondo de Cultura Económica.

Cioran, E. (1988). Historia y utopía. TusQuets.

Comisión Nacional de Verdad y Reconciliación (Rettig). (1991). Informe de la Comisión Nacional de Verdad y Reconciliación. Ministerio Secretaría General de Gobierno de Chile.

Comisión Nacional sobre Prisión Política y Tortura (Valech). (2004). Informe de la Comisión Nacional sobre Prisión Política y Tortura (Valech I). Salesianos Impresores.

Echeverry, L. y Jiménez De la Fuente, F. (26 de octubre de 2019). Protestas en Chile. BBC News. https://www. bbc.com/mundo/noticias-america-latina-50194456.

Elpidorou, A. (2020). Neglected Emotions. The Monist 103 (2), 135-146. doi: https://doi.org/10.1093/monist/ onz031.

Ferrer, C. (18 de octubre de 2019). Estudio ubica a Santiago en el top 10 del ranking del transporte público más caro en función del ingreso medio. El Mercurio. https://www.emol.com/noticias/ Nacional/2019/10/18/964843/Chile-9no-mas-carotransporte.html.

Friedman, M. (21 de abril de 1975). Carta a Pinochet. Economía y sociedad. https://www. economiaysociedad.cl/carta-milton-friedman-alpinochet.

Friedman, M. (2012). Commanding Heights Interview. On Freedom and Free Markets. En Ebenstein, L. (Ed.), The Indispensable Milton Friedmann (233235). Regnery.

Gardiner, M.E. (2019). A Tale of Two '68s. The "Politics of Boredom" in France and Italy. Cultural Politics 15 (3), 289-302. doi: https://doi.org/10.1215/174321977725437. 
Gobierno de Chile (23 de octubre de 2019). Presidente Piñera anuncia Agenda Social con mayores pensiones, aumento del ingreso mínimo, freno al costo de la electricidad, beneficios en salud, nuevos impuestos para altas rentas y defensoría para las víctimas de delitos. Prensa Presidencia. https:// prensa.presidencia.cl/comunicado.aspx?id=123766.

Kant, I. (2004). Antropología en sentido pragmático. Alianza.

Jadue Jadue, Ó. D. (2021). No lo vieron venir: Columnas, 2005-2020. LOM Ediciones.

Moya Arriagada, I. (10 de octubre de 2012). Por qué Chile no existe. El quinto poder. https://www.elquintopoder. cl/sociedad/por-que-chile-no-existe/.

Moya Arriagada, I. (19 de octubre de 2019). Once an Oasis of Stability, Chile now Burns. The Globe and Mail. https://www.theglobeandmail.com/opinion/ article-once-an-oasis-of-stability-chile-now-burns/.

Neu, J. (1998). Boring from Within: Endogenous Versus Reactive Boredom. En Flack Jr., W. F. y Laird J. D. (Eds.), Series in Affective Science (158-170). Oxford University Press.

Pinochet, A. (5 de marzo de 2000). El pueblo chileno se aburre, como se aburrió de mí. El País. https://elpais.com/diario/2000/03/06/ internacional/952297203_850215.html.

Retana, C. (2011). Consideraciones acerca del aburrimiento como emoción moral. Revista Káñina 35 (2), 179-190. doi: https://doi.org/10.15517/ rk.v35i2.561.
Revers, W. J. (1967). Perspectivas antropológicas del aburrimiento. Convivium 23, 38-47.

Ros Velasco, J. (2017). El aburrimiento como presión selectiva en Hans Blumenberg. Tesis Doctoral. Universidad Complutense de Madrid.

Ros Velasco, J. (2021). La pandemia del aburrimiento durante el confinamiento por la COVID-19. En Villacañas Berlanga, J. L. (Ed.), Pandemia. Ideas en la encrucijada (167-188). Biblioteca Nueva.

Ros Velasco, J. (2022 en prensa). La enfermedad del aburrimiento. Alianza.

Ross, K. (2002). May '68 and Its Afterlives. University of Chicago Press.

Sommer, D., Ros Velasco, J. y Abarca, M. (2021). Bored: A Pandemic of Domestic Violence. Partner Abuse 12 (1), 80-93. doi: https://doi.org/10.1891/PA-2020-0022.

Superintendencia de Pensiones (29 de noviembre de 2019). Superintendencia de Pensiones instruye a IPS y AFP para garantizar pago oportuno de nuevas pensiones solidarias desde diciembre de 2019. SP. https://www.spensiones. cl/portal/institucional/594/w3-article-13799.html.

Undurraga, J. (28 de noviembre de 2019). Cepal aborda desigualdad y estima que $1 \%$ más rico de Chile concentra el 22,6\% de los ingresos y riquezas del país.ElMercurio. https:// www.emol.com/noticias/Economia/2019/11/28/968758/ Cepal-1-mas-rico-Chile.html

Westgate, E. C. y Wilson, T. D. (2018). Boring Thoughts and Bored Minds: The MAC Model of Boredom and Cognitive Engagement. Psychological Review 125 (5), 689-713. doi: https://doi.org/10.1037/rev0000097. 